\title{
Study on the Relationship Between Core Competence and Fixed Surgery Specialty of Nurses in Operating Room
}

\author{
Yingyu Zeng ${ }^{1, ~ *}$, Xiaodan $\mathrm{Wu}^{2}$, Guiyin $\mathrm{Xu}^{1}$, Meifen $\mathrm{Zhang}^{3}$ \\ ${ }^{1}$ Operating Room, The First Hospital Affiliated of Sun Yat-Sen University, Guangzhou, China \\ ${ }^{2}$ Colorectum Department, Cancer Prevention and Control Center, Sun Yat-Sen University, Guangzhou, China \\ ${ }^{3}$ School of Nursing, Sun Yat-Sen University, Guangzhou, China \\ Email address: \\ 714800303@qq.com (Yingyu Zeng),wxdzhongda@126.com (Xiaodan Wu), Gzxuguiyin@163.com (Guiyin Xu), \\ zhmfen@mail.sysu.edu.cn (Meifen Zhang) \\ ${ }^{*}$ Corresponding author
}

\section{To cite this article:}

Yingyu Zeng, Xiaodan Wu, Guiyin Xu, Meifen Zhang. Study on the Relationship Between Core Competence and Fixed Surgery Specialty of Nurses in Operating Room. American Journal of Nursing Science. Vol. 9, No. 1, 2020, pp. 19-22. doi: 10.11648/j.ajns.20200901.13

Received: November 24, 2019; Accepted: December 16, 2019; Published: January 7, 2020

\begin{abstract}
Core competence is important for high-risk and high-demand operating room nurses, while there are few reports on the core competence of operating room nurses and its influencing factors. This study was to investigate the core competence of nurses in operating room and to explore the effect of fixed surgery specialty on their core competence. The Competency Inventory for Registered Nurses scale, which includes 7 dimensions consisting of a total of 58 items, including ethics/legal practice, professional development ability, leadership ability, clinical nursing ability, interpersonal relationship ability, education/counseling ability and critical thinking/scientific research ability, was used to evaluate the core competence of nurses. Based on the core competence scale of registered nurses, the specific items of core competence of nurses in 5 operating rooms were added to investigate 408 operating room nurses in 8 Grade $3 \mathrm{~A}$ hospitals in Guangzhou. The total average score of core competence of nurses in operating room was $(2.80 \pm 0.54)$. The scores of core competence of nurses in fixed surgery specialty were higher than that in unfixed surgery specialty group $(\mathrm{P}<0.05)$. Fixed in a particular surgery specialty is beneficial to improve the core competence of nurses in operating room and improve the quality and efficiency of surgical nursing cooperation.
\end{abstract}

Keywords: Operating Rooms, Nurses, Core Competence, Specialized Department

\section{Introduction}

The core competence of nurses refers to the ability of individuals to combine knowledge, skills and judgment in their daily work and use them effectively, which reflects the knowledge, understanding and judgment, cognition and skills needed by nurses to complete their basic job duties, personal characteristics and posture [1]. In recent years, the core competence of nurses has been paid more and more attention, and it is regarded as an important reference for nurses' on-the-job training, performance appraisal, career development and talent selection [1-3]. Operating room is a professional special nursing unit, in which working environment, nature, nursing technical operation is different from the ward. Therefore, the core competence is also an essential index to measure the overall quality of operating room nurses.

The special department of fixed surgery specialty in operating room refers to the nurses who have been trained in the operating room are relatively fixed in a surgical room to cooperate with nursing, which remains unchanged for more than two years. Core competence is more important for high-risk, high-demand operating room nurses, but there are few reports on the large sample systematic research on the core competence of operating room nurses and its influencing factors. The purpose of our study was to explore the effect of fixed surgery specialty on the core competence of nurses in operating room, so as to provide reference for the post management of clinical nurses in operating room. 


\section{Objects and Methods}

\subsection{Objects}

Nurses in operating room of 8 Grade $3 \mathrm{~A}$ general hospitals in Guangzhou were investigated by questionnaire from September to December 2011. Inclusion criteria were as follow: (1) obtained and registered nurse practice certificate; (2) engaged in clinical nursing in operating room for more than 2 years; (3) agreed to participate in this study. Exclusion criteria were as follow: (1) not on duty during the investigation, such as maternity leave, sick leave, going out to study, etc.; (2) nurses who are not in the operating room or in the hospital.

\subsection{Methods}

\subsubsection{Survey Tools}

i. General information questionnaire

A self-designed general information questionnaire was designed, including nurses' sex, age, marital status, establishment type, educational background, working years in operating room, whether they had participated in ward rotation training, whether fixed surgery specialty, fixed surgery specialty and so on.

ii. Competency Inventory for Registered Nurses (CIRN) [4]

The Competency Inventory for Registered Nurses scale was used to evaluate the core competence of nurses. CIRN includes 7 dimensions consisting of a total of 58 items, including ethics/legal practice, professional development ability, leadership ability, clinical nursing ability, interpersonal relationship ability, education/counseling ability, critical thinking/scientific research ability. The score from 0 to 4 was used for each item. The higher the total score was, the more comprehensive the nurses' core competence was. If the score of a single dimension is higher, the nurse has a higher ability in the corresponding dimension. The overall Cronbach's $\alpha$ coefficient of the scale was 0.892, and the Cronbach's $\alpha$ coefficient of each dimension ranged from 0.791 to 0.860 .

As there is no perfect scale of core competence for operating room nurses, five specific items of core competence of operating room nurses consistent with CIRN scoring method were added to evaluate the core competence of operating room nurses according to relative study [5]. They were: (1) to pay close attention to the quality of work and arrange the workflow in an orderly and reasonable manner, so as to ensure that all tasks are completed on time, according to quality and according to quantity; (2) to identify the harmful factors in the environment in time and do a good job of occupational safety protection; (3) to choose the correct method of disinfection and sterilization; (4) to deal with difficult nursing tasks with confidence and sufficient confidence; (5) proficient in dealing with perceived, actual or potential, sudden or urgent physical or mental health problems Before the study, 40 nurses who met the inclusion criteria were investigated. The Cronbach's $\alpha$ coefficient was from 0.753 to 0.905 . Thirteen nursing and statistical experts unanimously evaluated the content validity of the scale, and the scale can be used to evaluate the core competence of nurses in the operating room.

\subsubsection{Investigation Method}

By using the method of questionnaire survey, the researchers used unified guidance language to fill out the questionnaire to the research objects. A total of 420 questionnaires were distributed, of which 408 valid questionnaires were collected and the effective recovery rate was $97.14 \%$.

\subsubsection{Statistical Analysis}

The collected information is numbered and recorded by two researchers using Epidata 3.0. The statistical software package SPSS 18.0 was used. The counting data were expressed by frequency and percentage, and the measurement data were expressed by mean and standard deviation. Two independent samples t-test was used to analyze the effect of fixed surgery department on nurses' core competence.

\section{Results}

\subsection{General Information}

All 408 operating room nurses were female, with ages ranging from 18 to 55 years old (mean \pm standard deviation: $26.94 \pm 2.43)$. Among these operating room nurses, 262 $(64.22 \%)$ were married and $146(35.78 \%)$ were unmarried. The establishment types of these nurses were 191 (46.81\%) for fixed establishment, 85 (20.83\%) for mobile establishment and $132(32.35 \%)$ for contract establishment. The educational qualifications of nurses in these operating rooms were 204 $(50.00 \%)$ in technical secondary schools, 126 (30.88\%) in junior colleges, and 78 (19.12\%) in undergraduates or above. The working years of the operating room nurses were 2 32 (4.78 \pm 0.34$)$ years, including which 250 nurses $(61.27 \%)$ have worked less than 5 years while 158 nurses (38.73\%) have worked more than 5 years. There were 97 operating room nurses $(23.77 \%)$ who received the ward rotation department training, and $311(76.23 \%)$ who did not receive the ward rotation training. $117(28.68 \%)$ nurses in the operating room had no fixed surgery department, 291 (71.32\%) had fixed surgery department. Among the nurses in the department of fixed surgery, there were 50 nurses in general surgery $(17.18 \%), 45$ in cardiothoracic surgery $(15.46 \%), 26$ in brain surgery $(8.93 \%), 39$ in orthopaedics $(13.40 \%)$ and 43 in urology $(14.78 \%)$. There were 49 cases of pediatric surgery $(16.84 \%)$ and 39 cases of obstetrics and gynaecology $(13.40 \%)$.

\subsection{Level of Core Competence of Nurses in the Operating Room (Table 1)}

The minimum value, maximum value, dimension scores and average scores of entries of ethics/legal practice, professional development ability, leadership ability, clinical nursing ability, interpersonal relationship ability, education/counseling ability, and critical thinking/scientific research ability were showed in table 1 . 
Table 1. Level of core competence of nurses in the operating room.

\begin{tabular}{llllll}
\hline Project & $\begin{array}{l}\text { Number of } \\
\text { entries }(\mathbf{n})\end{array}$ & Minimum value & maximum value & $\begin{array}{l}\text { Dimension } \\
\text { score }(\mathbf{x} \pm \mathbf{s})\end{array}$ & $\begin{array}{l}\text { Average score } \\
\text { of entries (x } \pm \mathbf{s})\end{array}$ \\
\hline Ethics/legal practice & 8 & 12 & 32 & $23.44 \pm 4.91$ & $2.93 \pm 0.61$ \\
Professional development ability & 6 & 8 & 24 & $17.10 \pm 3.68$ & $2.85 \pm 0.61$ \\
Leadership ability & 10 & 13 & 40 & $27.99 \pm 5.76$ & $2.80 \pm 0.58$ \\
Clinical nursing ability & 9 & 9 & 36 & $25.00 \pm 5.86$ & $2.78 \pm 0.65$ \\
Interpersonal relationship ability & 8 & 9 & 32 & $22.01 \pm 5.21$ & $2.75 \pm 0.65$ \\
Education/counseling ability & 7 & 10 & 28 & $19.25 \pm 4.24$ & $2.75 \pm 0.61$ \\
Critical thinking/scientific research ability & 10 & 9 & 40 & $26.61 \pm 6.41$ & $2.66 \pm 0.64$ \\
New items & 5 & 7 & 20 & $15.13 \pm 3.39$ & $3.02 \pm 0.68$ \\
Total scores & 63 & 94 & 240 & $176.62 \pm 34.09$ & $2.80 \pm 0.54$ \\
\hline
\end{tabular}

\subsection{Influences of Fixed Surgery Specialty on Core Competence of Nurses (Table 2)}

Compared with unfixed surgery specialty group, the CIRN scores were significant higher in fixed surgery specialty group in ethics/legal practice $(27.45 \pm 5.71$ vs $24.54 \pm 7.52$; $\mathrm{P}=0.007<0.05)$, professional development ability $(25.64 \pm 5.69$ vs $23.42 \pm 6.00 ; \mathrm{P}=0.008<0.05)$, leadership ability $(28.86 \pm 5.62$ vs $25.85 \pm 5.56 ; \quad \mathrm{P}=0.001<0.05)$, clinical nursing ability $(23.11 \pm 4.57$ vs $19.27 \pm 5.69 ; \quad \mathrm{P}=0.000<0.05)$, interpersonal relationship ability $(23.99 \pm 5.03$ vs $22.06 \pm 4.32 ; \mathrm{P}=0.007<0.05)$, education/counseling ability (17.70 \pm 3.51 vs $15.60 \pm 3.51$; $\mathrm{P}=0.000<0.05)$, critical thinking/scientific research ability $(19.97 \pm 4.22$ vs $17.47 \pm 3.74 ; \mathrm{P}=0.000<0.05)$. The score of new items and total score were also higher in fixed surgery specialty group than that in unfixed surgery specialty group.

Table 2. Influences of fixed surgery specialty on core competence of nurses.

\begin{tabular}{|c|c|c|c|c|}
\hline Project & Fixed surgery specialist $(\mathrm{n}=\mathbf{2 9 1})$ & Unfixed surgery specialist $(n=117)$ & t value & Pvalue \\
\hline Ethics/legal practice & $27.45 \pm 5.71$ & $24.54 \pm 7.52$ & 3.771 & 0.007 \\
\hline Professional development ability & $25.64 \pm 5.69$ & $23.42 \pm 6.00$ & 3.512 & 0.008 \\
\hline Leadership ability & $28.86 \pm 5.62$ & $25.85 \pm 5.56$ & 4.902 & 0.001 \\
\hline Clinical nursing ability & $23.11 \pm 4.57$ & $19.27 \pm 5.69$ & 6.505 & 0.000 \\
\hline Interpersonal relationship ability & $23.99 \pm 5.03$ & $22.06 \pm 4.32$ & 3.623 & 0.007 \\
\hline Education/counseling ability & $17.70 \pm 3.51$ & $15.60 \pm 3.51$ & 5.415 & 0.000 \\
\hline Critical thinking/scientific research ability & $19.97 \pm 4.22$ & $17.47 \pm 3.74$ & 5.584 & 0.000 \\
\hline Total scores & $182.00 \pm 31.95$ & $163.23 \pm 35.65$ & 4.953 & 0.001 \\
\hline
\end{tabular}

\section{Discussion}

\subsection{The Core Competence of Nurses in Operating Room Is in the Upper-middle Level}

The results of our study showed that the total average score of core competence of nurses in operating room of 8 Grade $3 \mathrm{~A}$ general hospitals in Guangzhou was $(2.80 \pm 0.54)$, which was above the middle level, which was lower than that of nurses in related studies [6]. This may be due to the nurses in this group are from the operating room, heavy workload, physical strength and energy after work in a state of fatigue, affecting their enthusiasm to strengthen their own learning and update the knowledge structure, so the score of core competence is low. The nurses in the operating room in this survey come from Grade 3A Hospital. They were in better working environment and they have more learning opportunities and received stricter training and examination. The results of our study showed the core competence of nurses in the operating room was in the upper-middle level and it need to be further improved.

The new items in this survey have the highest scores, indicating that the nurses in this group have strong professional work ability. They can complete all kinds of operations with high quality and high efficiency, and have sufficient confidence in completing difficult nursing tasks. Operating room nurses are trained in their work and reflect the working characteristics of the operating room nurses. The level of legal/ethical practice ability was also high, indicating that the legal awareness of nurses in the operating room in China is gradually strengthening, which break the previous situation of weak legal awareness of nurses so as to protect the client while avoiding harm [2, 7]. This is inseparable from China's social progress, the gradual improvement of legislation, the enhancement of patients' legal awareness, and the emphasis on quality and safety in hospital management. The lowest score in the operating room nurses' core competence was education/consultation and critical thinking/scientific research ability. Critical thinking/scientific research ability was the most lacking aspect of nurses' core competence, which was the same for Nurses in different departments and different countries [8,9], especially in China. It is possible that the low educational background of nurses in most countries and regions leads to the overall lack of their scientific research ability [10]. Lack of solid theoretical knowledge leads to a low level of education/consultation. This result indicates that although the intensity of higher education is increasing and the cultivation of critical thinking/scientific research ability has been gradually valued by colleges and 
universities in recent years, operating room nurses are still in the process of learning. The traditional mode of thinking is still used to analyze problems, and there is no clear and unified critical thinking as guidance [11]. It is still in theory, and no critical/scientific research thinking has been put into practice, and the clinical education/consultation ability is also low.

\subsection{Operating Room Nurses with Fixed Surgery Specialty Have Higher Core Competence}

The results of this study showed that, in addition to the new entries, the scores of the core competence and the scores of the nurses who were fixed in a surgical specialty were higher than those of the non-fixed. This was consistent with the claim of professional management of the operating room personnel [12]. The reasons were as follow. First, nurses fixed in a surgical specialty can repeatedly improve and summarize the nursing methods of the patients with this special surgery. Their nursing ability, proficiency and ability to solve the problems of the specialist patients are better improved so that they can raise better questions, solve problems, and apply existing results to clinical practice. Second, the intensity of work in the operating room is relatively large, and the nursing of patients in operation varies greatly among different specialties. The nurses, who do not fix specialized subject turns between different operation specialized subject, have to learn the operating procedure of different operation ceaselessly, master the characteristic of different operation, and adapt to different doctor and intraoperative environment. These make the nurses easily exhausted physically and mentally. Operating room nurses can only be busy with the daily operation coordination work, which makes it difficult to take care of and improve their core abilities.

\section{Conclusion}

With the development of medical care and the continuous innovation of technology, the specialization of specialist nurses and nursing technology has gained more attention gradually. The results of our study suggest that the operation room nurses' relatively fixed cooperation with a certain surgery specialty is conducive to improve the core competence of the operation room nurses and the quality and efficiency of the operation room nurses' cooperation. This can meet the actual needs of the operation doctors and patients to the greatest extent, and better promote the development of the operation room nursing career.

\section{References}

[1] Alexander MF, PJ Runciman. ICN framework of competencies for the generalist nurse: Report of the development process and consultation. (2003). International Council of Nurses.

[2] Hughes A, D Galbraith, D White. Perceived competence: A common core for self-efficacy and self-concept? Journal of Personality Assessment, 2011, 93: 278-289.

[3] Axley L. (2008). Competency: A concept analysis. In: Nursing forum. Wiley Online Library. pp 214-222.

[4] Liu M, L Yin, E Ma. Confirmatory factor analysis of competency inventory for registered nurse. Chinese Journal of Nursing, 2008, 43: 204.

[5] Guo J, Q Li, L Wang, Y Yang, Y Li. Current status of research on core competence of operating room nurses. Chinese Nursing Management, 2012, 12: 64-66.

[6] Song C, J Wang. Quantitative study of nurse core competency and influence analysis of demographic variable. Chinese Journal of Nursing, 2009, 44: 11-14.

[7] Axson SA, NA Giordano, RM Hermann, CM Ulrich. Evaluating nurse understanding and participation in the informed consent process. Nurs Ethics, 2019, 26: 1050-1061.

[8] Lin Y, L Pan, S Tan, G Peng. Evaluation of phased effect of hierarchical core competence training for operating room professional nurses. Journal of Nursing, 2010, 17: 25-27.

[9] Song R. The value of nurse core competence training in continuous quality improvement in operating room. Chinese Practical Medicine, 2011, 6: 266-267.

[10] Wu X, X Liu. The research capacity of nursing staff and the status of scientific research achievements. Modern Clinical Nursing, 2009, 8: 71-74+70.

[11] Damron-Rodriguez J. Developing competence for nurses and social workers. Journal of Social Work Education, 2008, 44: 27-37.

[12] Sun H, Q Qian. Practice and experience of multi-disciplinary group management in comprehensive operating room nursing human resources. Nursing Journal of Chinese People's Liberation Army, 2006: 75-76. 